Article

\title{
High Myopia and Its Associated Factors in JPHC-NEXT Eye Study: A Cross-Sectional Observational Study
}

\author{
Kiwako Mori ${ }^{1,2}$, Toshihide Kurihara ${ }^{1,2, * \mathbb{D}}$, Miki Uchino ${ }^{1}$, Hidemasa Torii ${ }^{1,2}$, \\ Motoko Kawashima ${ }^{1}$, Mariko Sasaki ${ }^{1}$, Yoko Ozawa ${ }^{1} \mathbb{D}$, Kazumasa Yamagishi ${ }^{3, * \mathbb{D}}$, \\ Hiroyasu Iso ${ }^{4}$, Norie Sawada ${ }^{5}$, Shoichiro Tsugane ${ }^{5}$ (D), Kenya Yuki ${ }^{1}$ and Kazuo Tsubota ${ }^{1}$ (D) \\ 1 Department of Ophthalmology, Keio University School of Medicine, 35 Shinanomachi, Shinjuku-ku, \\ Tokyo 160-8582, Japan; morikiwako@gmail.com (K.M.); uchinomiki@yahoo.co.jp (M.U.); \\ htorii@2004.jukuin.keio.ac.jp (H.T.); motoko326@gmail.com (M.K.); mariko.sasaki@a2.keio.jp (M.S.); \\ ozawa@a5.keio.jp (Y.O.); yukikenya114@gmail.com (K.Y.); tsubota@z3.keio.jp (K.T.) \\ 2 Laboratory of Photobiology, Keio University School of Medicine, 35 Shinanomachi, Shinjuku-ku, \\ Tokyo 160-8582, Japan \\ 3 Department of Public Health Medicine, Faculty of Medicine, and Health Services Research and \\ Development Center, University of Tsukuba, 1-1-1 Tennodai, Tsukuba, Ibaraki 305-8575, Japan \\ 4 Public Health, Department of Social Medicine, Osaka University, Graduate School of Medicine, \\ Osaka University Graduate School of Medicine, 2-2 Yamadaoka, Suita, Osaka 565-0871, Japan; \\ iso@pbhel.med.osaka-u.ac.jp \\ 5 Epidemiology and Prevention Group, Center for Public Health Sciences, National Cancer Center, \\ 5-1-1 Tsukiji, Chuo-ku, Tokyo 104-0045, Japan; nsawada@ncc.go.jp (N.S.); stsugane@ncc.go.jp (S.T.) \\ * Correspondence: kurihara@z8.keio.jp (T.K.); yamagishi.kazumas.ge@u.tsukuba.ac.jp (K.Y.); \\ Tel.: +81-3-5363-3204 (T.K.); +81-29-853-2695 (K.Y.)
}

Received: 22 September 2019; Accepted: 22 October 2019; Published: 25 October 2019

\begin{abstract}
The increasing prevalence of high myopia has been noted. We investigated the epidemiological characteristics and the related factors of high myopia in a Japanese adult population. Japan Public Health Center-Based Prospective Study for the Next Generation (JPHC-NEXT) Eye Study was performed in Chikusei-city, a rural area in mid-east Japan, between 2013 and 2015. A cross-sectional observational analysis was conducted to investigate prevalence and related factors of high myopia. A total of 6101 participants aged $\geq 40$ years without a history of ocular surgeries was included. High myopia was defined as a spherical equivalent refraction of $\leq-6.00$ diopters according to the American Academy of Ophthalmology. Potential high myopia-related factors included intraocular pressure (IOP), corneal structure, corneal endothelial cell density, age, height, body mass index, heart rate, blood pressure, biochemical profile, and current history of systemic and ocular disorders. The odds ratios of high myopia were estimated using the logistic regression models adjusted for the associated factors. The prevalence of high myopia was 3.8\% in males and 5.9\% in females with a significant difference. Age was inversely associated, IOP was positively associated, and none of other factors were associated with high myopia in both sexes. In conclusion, only age and IOP were associated with high myopia in this community-based sample.
\end{abstract}

Keywords: high myopia; intraocular pressure; associated factors

\section{Introduction}

Myopia is one of the most prevalent conditions of the eye. It causes visual impairment in both children and adults that is usually correctable by optical aids such as glasses and contact lenses. 
High myopia is generally determined as -6.00 diopters (D) or less in refraction and axial lengths of $26.5 \mathrm{~mm}$ and more by the American Academy of Ophthalmology [1]. High myopia is associated with progressive and excessive elongation of the eyeball, which results in various funduscopic changes in the posterior fundus, and increases the risk of pathologic myopia, which may cause irreversible vision loss such as glaucoma, retinal detachment, and macular degeneration [2]. High myopia is a major cause of blindness in many countries [3], and the prevalence of myopia and high myopia is expected to increase globally from 2000 to 2050 [4]. Thus, it is important to manage myopia progression and to prevent myopia-related ocular complications and vision loss the approximately 1 billion people with high myopia [4].

Over the past few decades, some studies have provided information on the prevalence and risk factors for myopia, including genetic predisposition and environmental factors such as extended near work, less exercise, and luck of outdoor activities [5-7]. However, the etiology of myopia remains unclear. The length of indoor or outdoor activities [8-10], ethnicity [11], vitamins [12], diabetes [13], reading habits [14], body stature, lifestyles, and light environment [15-17] were suggested as associated factors for the progression of myopia.

Human lifestyles are rapidly changing. The factors that may affect the progression of myopia are essential to understanding and to finding countermeasures for myopia. Community-based population-based research is a reliable way to elucidate the associated factors. In order to elicit the high-myopia-associated factors, it was thought to be important to eliminate biases and prejudices as much as possible. We established this study to screen all the possible factors which were available in the collected data and personal information without manipulation. In addition, this study targeted adult population as subjects. Pathological myopia, which is usually preceded by high myopia and seen mostly in adults, is theoretically thought to be originated from myopia in children. To know possible associated factors for high myopia in adults is considered to be a crucial key to render solutions to diminish the number of future high or pathological myopia in children.

We conducted the Japan Public Health Center-Based Prospective Study for the Next Generation (JPHC-NEXT) Eye Study, an ancillary study of the JPHC-NEXT, to examine the prevalence of refractive status of the participants and factors associated with high myopia in Chikusei, a rural city in mid-east Japan. To our knowledge, this is the first large, community-based study to determine the factors associated with high myopia.

\section{Materials and Methods}

\subsection{Ethics Approval and Consent to Participate}

This study followed the tenets of the World Medical Association's Declaration of Helsinki. The study protocol was approved by the Institutional Review Boards of Keio University, Osaka University, the University of Tsukuba, and the National Cancer Center. Written informed consent was obtained from all the participants.

\subsection{Study Design and Participants}

JPHC-NEXT Eye Study was performed in two regions: Saku-city and Chikusei-city. The subjects of this study are participants of annual checkups who are aged 40 years or more in Chikusei-city, and a total of 7098 subject who had taken ocular examination between 2013 and 2015 were included in this study. Out of them, 997 participants who had undergone ocular surgeries were excluded because their refraction may have changed after the procedures. In the end, 6101 participants aged from 40 to 93 years $(86.0 \%)$ were included in this analysis (Figure 1 ). 


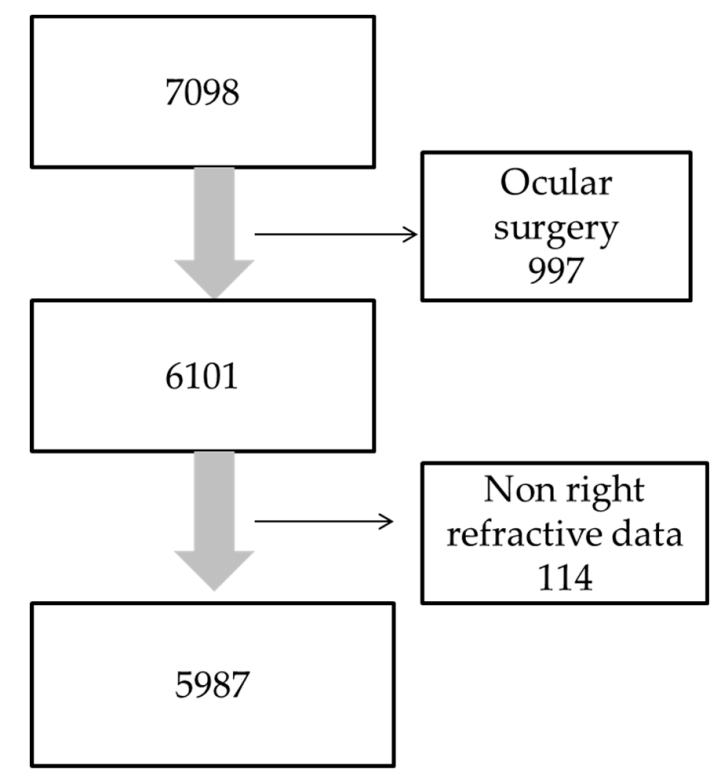

Figure 1. Study flow chart of this study. The number of participants who were 40 years old and over was 7098. Of them, 5987 participants were defined as the subjects after excluding 997 participants who had a history of ocular surgery and 114 participants who did not have refractive indices of their right eye.

\subsection{Screening Examination}

The screening included ophthalmic examinations (refraction, intraocular pressure, central corneal thickness, and corneal endothelium density); measurement of height (HT); weight (WT); blood pressure; and serum laboratory data including glutamic oxaloacetic transaminase (GOT), glutamic pyruvic transaminase (GPT), gamma-glutamyl transpeptidase (GGTP), total cholesterol (T cholesterol), fasting triglyceride (triglycerides), high density lipoprotein (HDL cholesterol), low density lipoprotein (LDL cholesterol), fasting blood glucose (glucose), hemoglobin A1c (HbA1c), and creatinine; and a history of systemic and ocular disorders. Serum T cholesterol, triglycerides, HDL cholesterol, LDL cholesterol, $\mathrm{HbA1c}$, GGTP, and creatinine were measured by visible absorption spectrometry. Serum glucose, GOT, and GPT were measured using ultraviolet absorption spectrometry. Blood pressure was measured two times, and the second reading was adopted. Height and body weight were measured with AD-6350 (A\&D Company Ltd., Tokyo, Japan). For blood pressure, TN2657P, TM 2657P, TM 2655P, and UM-102 (A\&D Company Ltd., Tokyo, Japan) were used; for biochemical examinations, BM8060G (NDK Inc., Sagamihara, Japan), LUMIPULSE ${ }^{\circledR}$ G1200 (FUJIREBIO Inc., Tokyo, Japan) and AIA2000 (Tosoh Corp., Tokyo, Japan) were used; and for blood glucose tests, BM9130 (NDK Inc., Sagamihara, Japan) was used. Refractive status and intraocular pressure (IOP) were measured using an auto refractometer (Tonoref II, Nidek, Gamagori, Japan). Central corneal thickness and corneal endothelium density were measured by using a specular-type pachymeter (Specular microscope XIII, Konan, Nishinomiya, Japan).

\subsection{Information on Past Medical History}

Information on histories of hypertension, diabetes, and dyslipidemia was collected through face-to-face interviews at the baseline survey. Likewise, inquiry about smoking history and alcohol history as well as histories of ocular disease and its surgery were also performed.

\subsection{Definitive Examination}

The spherical equivalent refraction (SEq) was calculated from the refraction using the following formula: the full spherical power plus half of the cylindrical power. Initially, the mean values of the SEq of the right eyes and the left eyes were compared in the entire population of the current study. 
There was no significant difference in the median SEq between the right eyes and the left eyes $(-0.13$ vs $-0.00(\mathrm{D}), p=0.10$ ). Thus, we used the SEq of the right eyes to evaluate the refractive status in this study. A high myopia was defined as SEq of $-6.00 \mathrm{D}$ or less based on the American Academy of Ophthalmology criteria [1].

\subsection{Statistical Analysis}

The prevalence of high myopia was calculated in total participants, in men and women, and in the groups classified by age. Chi-square test for the prevalence of high/non-high myopia in each sex was performed. When it demonstrated significant difference, comparison of variables between high myopia and non-high myopia groups in each sex was performed; continuous variables showing parametric distribution were analyzed with Student's t-test, and variables showing nonparametric distribution were analyzed with Mann-Whitney U test. Logistic regression was used to estimate odds ratios (ORs) and $95 \%$ confidence intervals (CIs), adjusting for age and for likely possible risk factors associated with high myopia. Multivariate logistic analyses were performed using variables showing significant difference in each sex as adjustment factors, since variables showing significance $(p<0.05)$ are different from each other by comparison between non-high myopia and high myopia groups in both sexes. Units are different among variables, and therefore, they are categorized by quartiles. A $p$ value of less than 0.05 was considered statistically significant. Statistical analyses were performed with the SPSS version 23.0 for Windows (IBM, Armonk, NY, USA).

\section{Results}

\subsection{Participants}

Among a total of 5987 subjects, the numbers of men and women were 2427 and 3557, respectively. The prevalence of high myopia in the current study was 5.0\%, 3.8\% in men and $5.9 \%$ in women. High myopia was more prevalent among women than men $(p<0.001)$. According to the age distribution, the prevalence of high myopia in the $40 \mathrm{~s}, 50 \mathrm{~s}, 60 \mathrm{~s}, 70 \mathrm{~s}, 80 \mathrm{~s}$, and $90 \mathrm{~s}$ was $10.6 \%, 8.8 \%, 3.5 \%, 2.0 \%, 1.2 \%$, and $0.0 \%$, respectively (Figure 2). The median SEq of the right eyes in total was $-0.13 \mathrm{D}$, ranging from $-23.13 \mathrm{D}$ to $+10.25 \mathrm{D}$, with the 1st quartile at -1.38 and the 3rd quartile at $+0.88 \mathrm{D}$. In the men, the median SEq was $-0.13 \mathrm{D}$, ranging from $-18.88 \mathrm{D}$ to $+10.25 \mathrm{D}$, with the 1 st quartile at -1.25 and the 3rd quartile at $+0.88 \mathrm{D}$. In the women, the median SEq was $-0.13 \mathrm{D}$, ranging from $-23.13 \mathrm{D}$ to $+6.88 \mathrm{D}$, with the 1st quartile at -1.63 and the $3 r d$ quartile at $+0.88 \mathrm{D}$. The median SEq of the right eye was not significantly different between genders $(p=0.52)$.

\subsection{Associations Between Systemic Factors and High Myopia}

We evaluated the associations between systemic factors and high myopia (Table 1). The mean age for the high myopia group was significantly lower than the non-high myopia group ( $55.7 \pm 10.5 \mathrm{vs}$ $62.8 \pm 10.3$ years, $p<0.001$ ). The peak of the high myopia prevalence by age was from 40 to 49 years (6.2\% among the men and $13.0 \%$ among the women). The mean height for the high myopia group was significantly higher than others $(158.8 \pm 8.0$ vs $157.5 \pm 8.7 \mathrm{~cm}, p=0.009)$. A similar difference was also found in the age and heights of men and women, respectively (Table 1). No significant difference between the high myopia group and non-high myopia group was observed in weight, waist, and diastolic blood pressure. Among the laboratory data, T cholesterol, triglycerides, and LDL cholesterol were significantly different between the two groups in men. Glucose and $\mathrm{HbA1c}$ were significantly different between the two groups in the women. Regarding the relationship between alcohol intake and high myopia, ORs for high myopia and alcohol intake history were 1.166 (95\%CI 0.371-3.662) in the men and 0.900 (95\% CI 0.467-1.732) in the women. ORs for high myopia and tobacco use history were 0.598 (95\%CI 0.340-1.051) in the men and 0.967 (95\%CI 0.593-1.577) in the women (Table S1). 
a
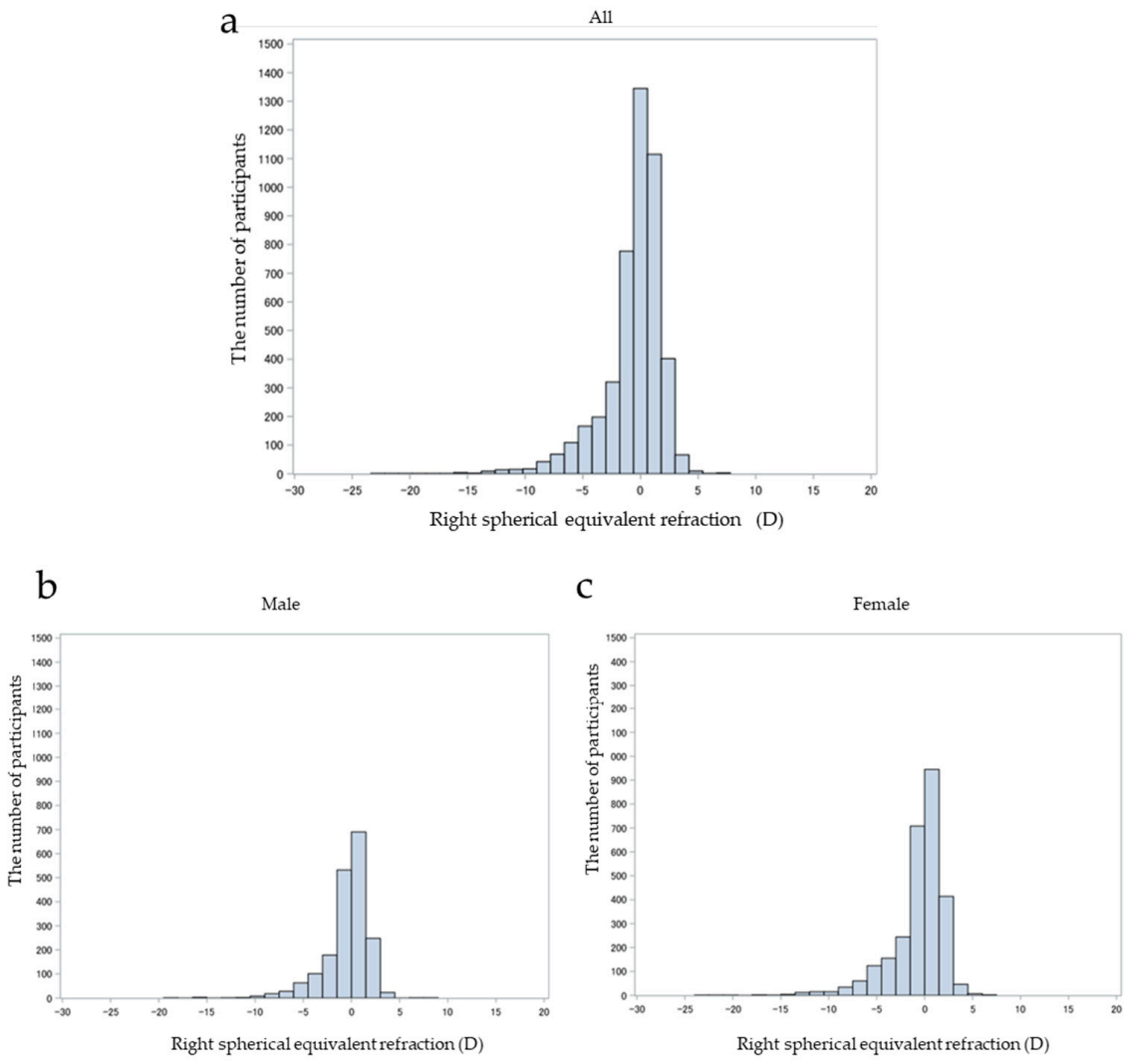

Figure 2. Distribution of spherical equivalent refraction in Chikusei-city: (a) the distribution map shows the spherical equivalent refraction of the right eye in the subjects, (b) spherical equivalent refraction of the right eye in men subjects, and (c) spherical equivalent refraction of the right eye in women subjects.

Table 1. The association between systemic and ocular features and high myopia.

\begin{tabular}{|c|c|c|c|}
\hline \multirow[b]{2}{*}{ Variables } & \multicolumn{2}{|c|}{ Mean \pm SD } & \multirow[b]{2}{*}{$p$ Value } \\
\hline & Non-High Myopia & High Myopia & \\
\hline \multicolumn{4}{|l|}{ All $(n=5984)$} \\
\hline Age & $62.8 \pm 10.3$ & $55.7 \pm 10.5$ & $<0.001$ \\
\hline $\mathrm{HT}$ & $157.6 \pm 8.7$ & $158.8 \pm 8.0$ & 0.009 \\
\hline BMI & $23.2 \pm 3.3$ & $22.8 \pm 4.1$ & 0.093 \\
\hline HR & $63.8 \pm 13.5$ & $64.3 \pm 14.8$ & 0.669 \\
\hline SBP & $124.8 \pm 17.6$ & $121.0 \pm 18.9$ & 0.001 \\
\hline DBP & $74.4 \pm 11.6$ & $73.9 \pm 13.3$ & 0.504 \\
\hline GOT & $24.1 \pm 37.9$ & $22.1 \pm 8.4$ & 0.422 \\
\hline GPT & $21.3 \pm 31.7$ & $20.6 \pm 12.9$ & 0.737 \\
\hline GGTP & $34.0 \pm 43.9$ & $30.0 \pm 24.3$ & 0.022 \\
\hline T CHOL & $209.4 \pm 35.6$ & $213.0 \pm 35.0$ & 0.082 \\
\hline TG & $96.0^{+}$ & $84.0^{\dagger}$ & $0.595^{+\dagger}$ \\
\hline HDL CHOL & $63.1 \pm 15.7$ & $65.3 \pm 15.4$ & 0.034 \\
\hline LDL CHOL & $126.7 \pm 31.7$ & $130.8 \pm 31.7$ & 0.052 \\
\hline GLU & $96.0^{\dagger}$ & $93.0^{\dagger}$ & $<0.001^{+\dagger}$ \\
\hline HbA1c & $5.8 \pm 0.7$ & $5.7 \pm 0.5$ & 0.004 \\
\hline Creatinine & $0.7 \pm 0.3$ & $0.7 \pm 0.1$ & 0.014 \\
\hline IOP & $13.3^{\dagger}$ & $14.3^{\dagger}$ & $<0.001^{+\dagger}$ \\
\hline Corneal radius & $7.6^{+}$ & $7.6^{+}$ & $0.070^{++}$ \\
\hline Central corneal thickness & $553.0^{+}$ & $557.0^{+}$ & $0.102^{+\dagger}$ \\
\hline Corneal endothelial cell number & $2747.0^{\dagger}$ & $2740.0^{\dagger}$ & $0.174^{\dagger+}$ \\
\hline
\end{tabular}


Table 1. Cont.

\begin{tabular}{|c|c|c|c|}
\hline \multirow[b]{2}{*}{ Variables } & \multicolumn{2}{|c|}{ Mean \pm SD } & \multirow[b]{2}{*}{$p$ Value } \\
\hline & Non-High Myopia & High Myopia & \\
\hline \multicolumn{4}{|l|}{$\operatorname{Men}(n=2427)$} \\
\hline Age & $64.2 \pm 10.4$ & $58.7 \pm 11.2$ & $<0.001$ \\
\hline $\mathrm{HT}$ & $164.8 \pm 6.5$ & $166.7 \pm 6.4$ & 0.007 \\
\hline BMI & $23.8 \pm 3.1$ & $24.3 \pm 4.2$ & 0.169 \\
\hline HR & $62.6 \pm 13.7$ & $63.4 \pm 14.5$ & 0.666 \\
\hline SBP & $128.6 \pm 17.1$ & $129.4 \pm 17.9$ & 0.684 \\
\hline DBP & $76.8 \pm 11.6$ & $78.5 \pm 12.4$ & 0.176 \\
\hline GOT & $26.4 \pm 58.1$ & $23.6 \pm 8.0$ & 0.677 \\
\hline GPT & $24.7 \pm 47.3$ & $24.9 \pm 12.1$ & 0.972 \\
\hline GGTP & $46.3 \pm 58.7$ & $40.0 \pm 24.2$ & 0.374 \\
\hline T CHOL & $119.3 \pm 33.7$ & $209.3 \pm 31.3$ & 0.003 \\
\hline TG & $105.0^{+}$ & $117.0^{+}$ & $0.023^{+\dagger}$ \\
\hline HDL CHOL & $57.0 \pm 14.5$ & $56.4 \pm 13.7$ & 0.733 \\
\hline LDL CHOL & $121.0 \pm 30.7$ & $129.7 \pm 29.9$ & 0.020 \\
\hline GLU & $99.0^{+}$ & $99.0^{+}$ & $0.597^{+\dagger}$ \\
\hline HbA1c & $5.8 \pm 0.8$ & $5.7 \pm 0.5$ & 0.215 \\
\hline Creatinine & $0.9 \pm 0.3$ & $0.9 \pm 0.1$ & 0.733 \\
\hline IOP & $13.3^{\dagger}$ & $15.0^{+}$ & $<0.001^{\text {t+ }}$ \\
\hline Corneal radius & $7.7^{\dagger}$ & $7.7^{\dagger}$ & $0.198^{\text {t+ }}$ \\
\hline Central corneal thickness & $556.0^{+}$ & $565.0^{+}$ & $0.391^{+\dagger}$ \\
\hline $\begin{array}{l}\text { Corneal endothelial cell number } \\
\text { Women }(n=3557)\end{array}$ & \multicolumn{2}{|c|}{ Women $(n=3557)$} & $0.538^{++}$ \\
\hline Age & $61.8 \pm 10.2$ & $54.4 \pm 9.9$ & $<0.001$ \\
\hline $\mathrm{HT}$ & $152.5 \pm 6.2$ & $155.4 \pm 5.9$ & 0.001 \\
\hline BMI & $22.8 \pm 3.5$ & $22.2 \pm 3.9$ & 0.012 \\
\hline HR & $64.6 \pm 13.4$ & $64.6 \pm 15.0$ & 0.964 \\
\hline SBP & $122.1 \pm 17.5$ & $117.4 \pm 18.2$ & $<0.001$ \\
\hline DBP & $72.7 \pm 11.3$ & $71.9 \pm 13.2$ & 0.358 \\
\hline GOT & $22.5 \pm 9.2$ & $21.5 \pm 8.5$ & 0.168 \\
\hline GPT & $19.0 \pm 11.7$ & $18.7 \pm 12.9$ & 0.815 \\
\hline GGTP & $25.4 \pm 26.2$ & $25.6 \pm 23.2$ & 0.920 \\
\hline T CHOL & $216.4 \pm 35.1$ & $214.6 \pm 36.4$ & 0.461 \\
\hline TG & $90.0^{\dagger}$ & $83.0^{\dagger}$ & $0.076^{\dagger+}$ \\
\hline HDL CHOL & $67.3 \pm 15.1$ & $69.2 \pm 14.4$ & 0.117 \\
\hline LDL CHOL & $130.6 \pm 31.8$ & $131.3 \pm 32.5$ & 0.783 \\
\hline GLU & $95.0^{+}$ & $91.0^{+}$ & $<0.001^{++}$ \\
\hline $\mathrm{HbA1c}$ & $5.8 \pm 0.6$ & $5.6 \pm 0.5$ & 0.011 \\
\hline Creatinine & $0.6 \pm 0.1$ & $0.6 \pm 0.1$ & 0.235 \\
\hline IOP & $13.7^{\dagger}$ & $14.0^{\dagger}$ & $0.038^{\dagger+}$ \\
\hline Corneal radius & $7.6^{+}$ & $7.6^{+}$ & $0.327^{\mathrm{t+}}$ \\
\hline Central corneal thickness & $551.0^{\dagger}$ & $553.5^{\dagger}$ & $0.159^{\dagger+}$ \\
\hline Corneal endothelial cell number & $2740.0^{\dagger}$ & $2725.0^{\dagger}$ & $0.159^{\dagger+}$ \\
\hline
\end{tabular}

Non-high myopia: SEq $>-6 \mathrm{D}$, High myopia: SEq $\leq-6 \mathrm{D} .{ }^{+}:$Median. ${ }^{++}:$Mann-Whitney U test. HT $=$height, BMI $=$ body mass index, $\mathrm{HR}=$ heart rate, $\mathrm{SBP}=$ systolic blood pressure, $\mathrm{DBP}=$ diastolic blood pressure, $\mathrm{GOT}=$ glutamicoxaloacetic transaminase, GPT = glutamate pyruvate transaminase, GGTP = gamma-glutamyl transpeptidase, $\mathrm{T} \mathrm{CHOL}=$ total cholesterol, $\mathrm{TG}=$ triglyceride, $\mathrm{HDL} \mathrm{CHOL}=$ high-density lipoprotein cholesterol, $\mathrm{LDL} \mathrm{CHOL}=$ low-density lipoprotein cholesterol, GLU = glucose, HbA1c = Hemoglobin A1c, IOP = intraocular pressure.

\subsection{Associated Between Ocular Features and High Myopia}

Associations between ocular features and high myopia were also evaluated (Table 1). The median IOP was significantly higher for the high myopia group than the others $(14.30 \mathrm{vs} 13.30 \mathrm{mmHg}, p<0.001)$. Similar differences were found in the median IOPs of the men or women, respectively. A significant difference was also observed in the median corneal radius between the high myopia group and the others (7.62 vs. $7.64 \mathrm{~mm}, p=0.024)$. However, no significant difference was found in the median 
corneal radii of the men and women, respectively. There was no significant difference in central corneal thickness and corneal endothelial cell number between the two groups.

\subsection{IOP and Age Associated with High Myopia}

A multivariable logistic regression analysis was performed to identify the factors associated with high myopia (Table 2 and Table S2). The ORs adjusted for multivariable factors were significant for age and IOP in the men and the women. In men, the values were as follows: the ORs adjusted with other factors for high myopia in each age group were $40-58$ years (OR 1 ), 59-65years (OR $0.44,95 \% \mathrm{CI}$ $0.22-0.89$ ), 66-70 years (OR $0.43,95 \% \mathrm{CI} 0.20-0.93$ ), and no younger than 71 years (OR $0.48,95 \% \mathrm{CI}$ $0.22-1.06, p$ for trend 0.049 ). The ORs adjusted with other factors for high myopia in the groups of IOP were $\leq 11.2 \mathrm{mmHg}$ (OR 1), 11.3-13.2 mmHg (OR 3.34, 95\%CI 0.93-12.00), 13.3-15.2 mmHg (OR 5.18, $95 \%$ CI 1.49-18.04), and $\geq 15.3 \mathrm{mmHg}$ (OR 7.73, 95\%CI 2.24-26.77), respectively ( $p$ for trend $<0.001$ ).

Table 2. Multivariate logistic regression analysis to identify factors associated with high myopia.

\begin{tabular}{|c|c|c|c|c|}
\hline & & OR & $95 \% \mathrm{CI}$ & $p$ Value \\
\hline \multicolumn{5}{|l|}{ Men } \\
\hline \multirow[t]{5}{*}{ Age } & $\leq 58$ & 1 & & \\
\hline & $59-65$ & 0.44 & $(0.221-0.886)$ & \\
\hline & $66-70$ & 0.43 & $(0.197-0.930)$ & \\
\hline & $\geq 71$ & 0.48 & (0.219-1.059) & \\
\hline & $p$ for trend & & & 0.049 \\
\hline \multirow[t]{5}{*}{ HT } & $\leq 160$ & 1 & & \\
\hline & $161-164$ & 0.95 & $(0.388-2.318)$ & \\
\hline & 165-168 & 1.42 & $(0.620-3.271)$ & \\
\hline & $\geq 169$ & 1.65 & $(0.722-3.784)$ & \\
\hline & $p$ for trend & & & 0.131 \\
\hline \multirow[t]{5}{*}{ BMI } & $\leq 21.6$ & 1 & & \\
\hline & $21.7-23.5$ & 1.41 & $(0.660-3.020)$ & \\
\hline & $23.6-25.6$ & 0.96 & $(0.423-2.188)$ & \\
\hline & $\geq 25.7$ & 1.07 & $(0.479-2.368)$ & \\
\hline & $p$ for trend & & & 0.836 \\
\hline \multirow[t]{5}{*}{ SBP } & $\leq 116$ & 1 & & \\
\hline & $117-127$ & 0.61 & $(0.272-1.364)$ & \\
\hline & 128-138 & 0.98 & (0.481-1.978) & \\
\hline & $\geq 139$ & 0.83 & $(0.396-1.741)$ & \\
\hline & $p$ for trend & & & 0.912 \\
\hline \multirow[t]{5}{*}{ TG } & $\leq 73$ & 1 & & \\
\hline & 74-105 & 2.93 & $(1.126-7.616)$ & \\
\hline & 106-149 & 3.10 & $(1.183-8.103)$ & \\
\hline & $\geq 150$ & 2.79 & $(1.018-7.619)$ & \\
\hline & $p$ for trend & & & 0.117 \\
\hline \multirow[t]{5}{*}{ HDL CHOL } & $\leq 46$ & 1 & & \\
\hline & $47-54$ & 0.78 & $(0.374-1.625)$ & \\
\hline & $55-64$ & 0.99 & $(0.473-2.065)$ & \\
\hline & $\geq 65$ & 1.14 & $(0.529-2.442)$ & \\
\hline & $p$ for trend & & & 0.682 \\
\hline \multirow[t]{5}{*}{ LDL CHOL } & $\leq 100$ & 1 & & \\
\hline & 101-119 & 2.07 & $(0.909-4.729)$ & \\
\hline & 120-139 & 1.44 & $(0.615-3.371)$ & \\
\hline & $\geq 140$ & 1.72 & $(0.758-3.892)$ & \\
\hline & $p$ for trend & & & 0.348 \\
\hline
\end{tabular}


Table 2. Cont.

\begin{tabular}{|c|c|c|c|c|}
\hline & & OR & $95 \%$ CI & $p$ Value \\
\hline \multirow[t]{5}{*}{$\mathrm{HbA1c}$} & $\leq 5.3$ & 1 & & \\
\hline & $5.4-5.5$ & 0.84 & (0.390-1.797) & \\
\hline & $5.6-5.9$ & 0.75 & $(0.355-1.579)$ & \\
\hline & $\geq 6.0$ & 0.83 & $(0.377-1.811)$ & \\
\hline & $p$ for trend & & & 0.453 \\
\hline \multirow[t]{5}{*}{ IOP } & $\leq 11.2$ & 1 & & \\
\hline & $11.3-13.2$ & 3.34 & $(0.927-12.002)$ & \\
\hline & $13.3-15.2$ & 5.18 & $(1.487-18.037)$ & \\
\hline & $\geq 15.3$ & 7.73 & $(2.235-26.768)$ & \\
\hline & $p$ for trend & & & $<0.001$ \\
\hline \multirow[t]{5}{*}{ Central corneal thickness } & $\leq 531$ & 1 & & \\
\hline & $532-556$ & 0.93 & $(0.421-2.053)$ & \\
\hline & $557-583$ & 1.05 & $(0.483-2.269)$ & \\
\hline & $\geq 584$ & 1.01 & $(0.471-2.180)$ & \\
\hline & $p$ for trend & & & 0.847 \\
\hline \multicolumn{5}{|l|}{ Women } \\
\hline \multirow[t]{5}{*}{ Age } & $\leq 54$ & 1 & & \\
\hline & $55-62$ & 0.57 & $(0.358-0.904)$ & \\
\hline & $63-68$ & 0.35 & $(0.208-0.586)$ & \\
\hline & $\geq 69$ & 0.21 & $(0.106-0.405)$ & \\
\hline & $p$ for trend & & & $<0.001$ \\
\hline \multirow[t]{5}{*}{$\mathrm{HT}$} & $\leq 147$ & 1 & & \\
\hline & $148-152$ & 0.88 & $(0.486-1.594)$ & \\
\hline & $153-156$ & 1.03 & $(0.571-1.872)$ & \\
\hline & $\geq 157$ & 1.35 & $(0.752-2.424)$ & \\
\hline & $p$ for trend & & & 0.195 \\
\hline \multirow[t]{5}{*}{ BMI } & $\leq 20.3$ & 1 & & \\
\hline & $20.4-22.3$ & 0.76 & (0.481-1.205) & \\
\hline & $22.4-24.6$ & 0.58 & (0.344-0.977) & \\
\hline & $\geq 24.7$ & 0.68 & (0.399-1.156) & \\
\hline & $p$ for trend & & & 0.120 \\
\hline \multirow[t]{5}{*}{ SBP } & $\leq 108$ & 1 & & \\
\hline & 109-120 & 0.74 & (0.458-1.191) & \\
\hline & 121-132 & 0.87 & (0.520-1.457) & \\
\hline & $\geq 133$ & 1.02 & $(0.605-1.729)$ & \\
\hline & $p$ for trend & & & 0.698 \\
\hline \multirow[t]{5}{*}{ TG } & $\leq 66$ & 1 & & \\
\hline & $67-89$ & 0.85 & (0.530-1.352) & \\
\hline & $90-124$ & 0.77 & $(0.455-1.288)$ & \\
\hline & $\geq 125$ & 0.94 & (0.547-1.619) & \\
\hline & $p$ for trend & & & 0.624 \\
\hline \multirow[t]{5}{*}{ HDL CHOL } & $\leq 56$ & 1 & & \\
\hline & $57-65$ & 1.37 & $(0.810-2.298)$ & \\
\hline & $66-75$ & 1.25 & $(0.735-2.116)$ & \\
\hline & $\geq 76$ & 1.02 & $(0.583-1.785)$ & \\
\hline & $p$ for trend & & & 0.801 \\
\hline \multirow[t]{5}{*}{ LDL CHOL } & $\leq 107$ & 1 & & \\
\hline & $108-127$ & 1.07 & $(0.629-1.830)$ & \\
\hline & $128-149$ & 2.07 & $(1.273-3.352)$ & \\
\hline & $\geq 150$ & 1.27 & $(0.744-2.149)$ & \\
\hline & $p$ for trend & & & 0.121 \\
\hline
\end{tabular}


Table 2. Cont.

\begin{tabular}{ccccc}
\hline & OR & 95\% CI & $p$ Value \\
\hline HbA1c & $\leq 5.4$ & 1 & & \\
& $5.5-5.6$ & 1.29 & $(0.833-1.993)$ & \\
$5.7-5.8$ & 0.85 & $(0.493-1.463)$ & \\
$\geq 5.9$ & 1.03 & $(0.618-1.731)$ & \\
& $p$ for trend & & & 0.738 \\
\hline IOP & $\leq 11.6$ & 1 & & \\
& $11.7-13.6$ & 2.23 & $(1.226-4.052)$ & \\
& $13.7-15.6$ & 2.25 & $(1.213-4.157)$ & \\
& $\geq 15.7$ & 2.33 & $(1.239-4.367)$ & \\
& $p$ for trend & & & \\
\hline Central corneal thickness & $\leq 524$ & 1 & & \\
& $525-550$ & 0.83 & $(0.508-1.361)$ & \\
& $551-574$ & 0.70 & $(0.423-1.164)$ & \\
& $\geq 575$ & 0.92 & $(0.561-1.523)$ & \\
& $p$ for trend & & & 0.730 \\
\hline
\end{tabular}

N on-high myopia: SEq > -6D, high myopia: SEq $\leq-6 \mathrm{D}$, OR: Adjusted by age, HT, BMI, SBP, TG, HDL CHOL, LDL CHOL, HbA1c, IOP, and central corneal thickness. HT = height, BMI = body mass index, SBP = systolic blood pressure, $\mathrm{TG}=$ triglyceride, $\mathrm{HDL} \mathrm{CHOL}=$ high-density lipoprotein cholesterol, $\mathrm{LDL} \mathrm{CHOL}=$ low-density lipoprotein cholesterol, $\mathrm{HbA1c}=$ Hemoglobin A1c, IOP = intraocular pressure.

In women, the values were as follows: the ORs adjusted with other factors for high myopia in each age group were $40-54$ years (OR 1), 55-62 years (OR 0.57, 95\%CI 0.36-0.90), 63-68 years (OR 0.35, 95\%CI $0.21-0.59$ ), and no younger than 69 years (OR $0.21,95 \% \mathrm{CI} 0.11-0.41)$ ( $p$ for trend $<0.001$ ). The ORs adjusted with other factors in each IOP group were $\leq 11.6 \mathrm{mmHg}$ (OR 1), 11.7-13.6 mmHg (OR 2.23, 95\%CI 1.23-4.05), 13.7-15.6 mmHg (OR 2.25, 95\%CI 1.21-4.16), and $\geq 15.7 \mathrm{mmHg}$ (OR 2.33, 95\%CI 1.24-4.37), respectively ( $p$ for trend 0.023). In summary, as the age increases, the OR decreases and, as the IOP increases, the OR increases in both men and women.

\section{Discussion}

This community-based study showed the prevalence of high myopia and associated factors including physical, ocular, and demographic factors among adult Japanese for the first time. The factors associated with myopia were widely investigated as we analyzed biochemistry tests, blood pressure, height, body weight, habit of smoking, alcohol intake, past medical history, and present diseases. In this current study, we found that high myopia is more prevalent in women and younger age and that it has higher IOP.

High myopia affects approximately $1-4 \%$ of adults aged $\geq 40$ years, and its prevalence was higher in some studies of East Asian adults and adolescents [18-25]. Our findings showed that the prevalence of high myopia was $5.0 \%$, which was no less than the generally affected rates, although Chikusei-city is in a rural area where its prevalence has usually been lower compared to urban areas [25]. In our study, the high myopia rate in the older population was relatively low and the younger generation had a higher prevalence of high myopia, which may reflect cohort effects. Although the reason for this cohort effects is unknown, the prevalence of high myopia could be expected to increase in the future.

Some previous studies reported the relationship of height [26-28] and BMI [29-31] with myopia; however, we did not find such association. A possible reason for this discrepancy is confounding; the previous reports did not adjust for age and any other confounding factors. In fact, BMI and height were shown to be associated with high myopia in unadjusted models and adjustment for age resulted in the elimination of this significance in our study, presumably because age is a strong predisposing factor for BMI and height reflecting cohort effects.

As for the other laboratory factors, there was no significant difference. A few studies suggested that hyperglycemia and hyperlipidemia led to myopic shift, whereas other studies revealed that the 
refractive shift was more likely hyperopic with hypoglycemia [32-35]. Further analysis is needed to elucidate the influence of metabolic shift.

In terms of alcohol intake and smoking history, both factors did not show any associations with high myopia according to our results. Also, liver functions, represented by GOT, GPT, and GGTP, did not show any relationship to high myopia. Previous reports also found that there were no significant trends observed between smoking and refractive errors [36].

The percentages of high myopia in men and women were $3.8 \%$ and $5.9 \%$, respectively, indicating significant gender difference. It has been reported that female sex had a predisposition of high myopia [37]. Likewise, female sex was proven to have high risk for myopic complications usually caused by high myopia [38]. Hyman et al. reported that female sex is independently associated with faster myopic progression [39], although there have been no reports describing causal relationship between gender and high myopia.

The mean IOP linearly increased parallel to the myopic progression. It has been reported that IOP was associated with central corneal thickness, age, and blood pressure [40,41]. Even after adjustment for these factors, we still found that high IOP was significantly associated with high myopia, while there are conflicting evidences regarding relationship of high myopia and IOP [42-44].

Although this cross-sectional study is to investigate the risk factors for high myopia through a large-scale cross-sectional study, a few studies with relatively small number of subjects were undertaken. Mo et al. [37] concluded in their study performed in a rural area in China with 167 participants that females may be a risk factor for myopia and that advanced age is a factor for decreased visual acuity. As for the results obtained from this large-scale study showing that being young, being a woman, and having high IOP are the risk factors for high myopia, we investigated previous articles regarding these factors. Matamoros et al. [45] reported in their study that prevalence of high myopia was higher in 20- to 39-year-old subjects as well as among women than men, which are consistent with our results. Otherwise, being a woman has well been reported to be a risk factor for myopia in some other studies [46]. Attebo et al. [46] also confirmed an age-related increase in hyperopia associated with an age-related decrease in myopia; however, a distinct association between high myopia and age has not been elucidated. Concerning relationships between high myopia and glaucoma, Chen et al. [47] reported high myopia as a risk factor in primary open angle glaucoma (POAG) and elevated intraocular pressure as a well-known major risk factor for POAG. Nevertheless, there have been no reports describing direct association between high IOP and high myopia.

There are some limitations in this study. First of all, the study design is not completely reasonable because the data used for the analysis are practically limited. Although the JPHC-NEXT study is large scale in terms of the participant number, it is basically a universal data collection based on regular checkups performed in a rural area. Therefore, this is not conducted specifically for ophthalmological analysis. The study would have been more informative if it contained questionnaires or interviews concerning the time for near-work and indoor/outdoor activities as well as academic levels and heredity of myopia. In addition, another limitation of this study is the lack of ophthalmological analysis including the measurement of axial length and lens corrections, which are crucial to determine the participants' classification of non-/high myopia. This study should be completed with these detailed data to make the conclusions more reliable; however, it could be done only beyond the limitation of this cross-sectional study. Owing to the large-scale study, instead, we were able to effectively assess a large number of basically healthy participants altogether and to draw these critical results. The factors associated with high myopia were undetermined. This study did not suggest that height, BMI, blood glucose, hypocholesteremia, liver dysfunction, kidney dysfunction, smoking, and alcohol intake were associated with high myopia, whereas women, young age, and high IOP were found to be related to high myopia. Meanwhile, high IOP and young age were found to be risk factors for high myopia, which may indicate the path for future studies concerning myopia control. 


\section{Conclusions}

In conclusion, this epidemiological study performed in a Japanese rural area revealed significant results: being a women, being young, and having high IOP were factors associated with high myopia, while height, BMI, cholesterol level, glucose level, and other considered possible risk factors for high myopia in previous studies were not associated with prevalence of myopia.

Supplementary Materials: The following are available online at http://www.mdpi.com/2077-0383/8/11/1788/s1, Table S1: The association between alcohol, tobacco and high myopia. Table S2: Logistic regression analysis to identify factors associated with high myopia.

Author Contributions: Conceptualization, K.M., T.K. M.U., K.Y. (Kenya Yuki), and K.T.; methodology, K.M., T.K., M.U., K.Y. (Kazumasa Yamagishi), N.S., and K.Y. (Kenya Yuki); formal analysis, K.M. and M.U.; investigation, K.M., M.U., M.K., K.Y. (Kazumasa Yamagishi), N.S., and K.Y. (Kenya Yuki); data curation, K.M., M.U., M.K., K.Y. (Kazumasa Yamagishi), N.S., and K.Y. (Kenya Yuki); project administration, K.M., T.K., M.U., K.Y. (Kazumasa Yamagishi), N.S., K.Y. (Kenya Yuki), and T.K.; writing-original draft preparation, K.M.; writing-review and editing, K.M., T.K., M.U., H.T., M.K., M.S., Y.O., K.Y. (Kazumasa Yamagishi), H.I., N.S., S.T., K.Y. (Kenya Yuki), and K.T.; supervision, H.I., S.T., and K.T. All authors made a substantial contribution in the revision of the manuscript.

Funding: Toshihide Kurihara: specified contribution from Keio University; Kenya Yuki: JSPS KAKENHI grant number JP16K11271, specified contribution from Keio University, and 2015 Novartis Research Grant; Kazuo Tsubota: specified contribution from Keio University; Shoichiro Tsugane: National Cancer Center Research and Development Fund.

Conflicts of Interest: The authors declare no conflict of interest.

\section{References}

1. Ikuno, Y.; Ohji, M. High Myopia and the Vitreoretina; Complocations. In Retina (Philadelphia, PA), 5th ed.; Ryan, S.J., Ed.; Elsevier: Los Angeles, CA, USA, 2013; Volume 3, pp. 1912-1919.

2. Wong, T.Y.; Ferreira, A.; Hughes, R.; Carter, G.; Mitchell, P. Epidemiology and disease burden of pathologic myopia and myopic choroidal neovascularization: An evidence-based systematic review. Am. J. Ophthalmol. 2014, 157, 9-25. [CrossRef] [PubMed]

3. Hsu, W.M.; Cheng, C.Y.; Liu, J.H.; Tsai, S.Y.; Chou, P. Prevalence and causes of visual impairment in an elderly Chinese population in Taiwan: The Shihpai Eye Study. Ophthalmology 2004, 111, 62-69. [CrossRef] [PubMed]

4. Holden, B.A.; Fricke, T.R.; Wilson, D.A.; Jong, M.; Naidoo, K.S.; Sankaridurg, P.; Wong, T.Y.; Naduvilath, T.J.; Resnikoff, S. Global Prevalence of Myopia and High Myopia and Temporal Trends from 2000 through 2050. Ophthalmology 2016, 123, 1036-1042. [CrossRef]

5. Goldschmidt, E.; Jacobsen, N. Genetic and environmental effects on myopia development and progression. Eye 2014, 28, 126-133. [CrossRef]

6. Dirani, M.; Chamberlain, M.; Shekar, S.N.; Islam, A.F.; Garoufalis, P.; Chen, C.Y.; Guymer, R.H.; Baird, P.N. Heritability of refractive error and ocular biometrics: The Genes in Myopia (GEM) twin study. Investig. Ophthalmol. Vis. Sci. 2006, 47, 4756-4761. [CrossRef]

7. Ramessur, R.; Williams, K.M.; Hammond, C.J. Risk factors for myopia in a discordant monozygotic twin study. Ophthalmic Physiol. Opt. J. Br. Coll. Ophthalmic Opt. Optom. 2015, 35, 643-651. [CrossRef] [PubMed]

8. Rose, K.A.; Morgan, I.G.; Smith, W.; Burlutsky, G.; Mitchell, P.; Saw, S.M. Myopia, lifestyle, and schooling in students of Chinese ethnicity in Singapore and Sydney. Arch. Ophthalmol. 2008, 126, 527-530. [CrossRef]

9. Wu, P.C.; Tsai, C.L.; Wu, H.L.; Yang, Y.H.; Kuo, H.K. Outdoor activity during class recess reduces myopia onset and progression in school children. Ophthalmology 2013, 120, 1080-1085. [CrossRef]

10. He, M.; Xiang, F.; Zeng, Y.; Mai, J.; Chen, Q.; Zhang, J.; Smith, W.; Rose, K.; Morgan, I.G. Effect of Time Spent Outdoors at School on the Development of Myopia Among Children in China: A Randomized Clinical Trial. JAMA 2015, 314, 1142-1148. [CrossRef]

11. Rudnicka, A.R.; Owen, C.G.; Nightingale, C.M.; Cook, D.G.; Whincup, P.H. Ethnic differences in the prevalence of myopia and ocular biometry in 10- and 11-year-old children: The Child Heart and Health Study in England (CHASE). Investig. Ophthalmol. Vis. Sci. 2010, 51, 6270-6276. [CrossRef] 
12. Tideman, J.W.; Polling, J.R.; Voortman, T.; Jaddoe, V.W.; Uitterlinden, A.G.; Hofman, A.; Vingerling, J.R.; Franco, O.H.; Klaver, C.C. Low serum vitamin D is associated with axial length and risk of myopia in young children. Eur. J. Epidemiol. 2016, 31, 491-499. [CrossRef] [PubMed]

13. Galvis, V.; Lopez-Jaramillo, P.; Tello, A.; Castellanos-Castellanos, Y.A.; Camacho, P.A.; Cohen, D.D.; Gomez-Arbelaez, D.; Merayo-Lloves, J. Is myopia another clinical manifestation of insulin resistance? Med. Hypotheses 2016, 90, 32-40. [CrossRef] [PubMed]

14. Hsu, C.C.; Huang, N.; Lin, P.Y.; Tsai, D.C.; Tsai, C.Y.; Woung, L.C.; Liu, C.J. Prevalence and risk factors for myopia in second-grade primary school children in Taipei: A population-based study. J. Chin. Med. Assoc. 2016, 79, 625-632. [CrossRef] [PubMed]

15. Torii, H.; Ohnuma, K.; Kurihara, T.; Tsubota, K.; Negishi, K. Violet Light Transmission is Related to Myopia Progression in Adult High Myopia. Sci. Rep. 2017, 7, 14523. [CrossRef]

16. Torii, H.; Kurihara, T.; Seko, Y.; Negishi, K.; Ohnuma, K.; Inaba, T.; Kawashima, M.; Jiang, X.; Kondo, S.; Miyauchi, M.; et al. Violet Light Exposure Can Be a Preventive Strategy Against Myopia Progression. EBioMedicine 2017, 15, 210-219. [CrossRef]

17. Karouta, C.; Ashby, R.S. Correlation between light levels and the development of deprivation myopia. Investig. Ophthalmol. Vis. Sci. 2014, 56, 299-309. [CrossRef]

18. Ezelum, C.; Razavi, H.; Sivasubramaniam, S.; Gilbert, C.E.; Murthy, G.V.; Entekume, G.; Abubakar, T. Refractive error in Nigerian adults: Prevalence, type, and spectacle coverage. Investig. Ophthalmol. Vis. Sci. 2011, 52, 5449-5456. [CrossRef]

19. Liang, Y.B.; Wong, T.Y.; Sun, L.P.; Tao, Q.S.; Wang, J.J.; Yang, X.H.; Xiong, Y.; Wang, N.L.; Friedman, D.S. Refractive errors in a rural Chinese adult population the Handan eye study. Ophthalmology 2009, 116, 2119-2127. [CrossRef]

20. Pan, C.W.; Wong, T.Y.; Lavanya, R.; Wu, R.Y.; Zheng, Y.F.; Lin, X.Y.; Mitchell, P.; Aung, T.; Saw, S.M. Prevalence and risk factors for refractive errors in Indians: The Singapore Indian Eye Study (SINDI). Investig. Ophthalmol. Vis. Sci. 2011, 52, 3166-3173. [CrossRef]

21. Saw, S.M.; Gazzard, G.; Koh, D.; Farook, M.; Widjaja, D.; Lee, J.; Tan, D.T. Prevalence rates of refractive errors in Sumatra, Indonesia. Investig. Ophthalmol. Vis. Sci. 2002, 43, 3174-3180.

22. Tarczy-Hornoch, K.; Ying-Lai, M.; Varma, R. Myopic refractive error in adult Latinos: The Los Angeles Latino Eye Study. Investig. Ophthalmol. Vis. Sci. 2006, 47, 1845-1852. [CrossRef] [PubMed]

23. Wang, T.J.; Chiang, T.H.; Wang, T.H.; Lin, L.L.; Shih, Y.F. Changes of the ocular refraction among freshmen in National Taiwan University between 1988 and 2005. Eye 2009, 23, 1168-1169. [CrossRef] [PubMed]

24. Wong, T.Y.; Foster, P.J.; Hee, J.; Ng, T.P.; Tielsch, J.M.; Chew, S.J.; Johnson, G.J.; Seah, S.K. Prevalence and risk factors for refractive errors in adult Chinese in Singapore. Investig. Ophthalmol. Vis. Sci. 2000, 41, 2486-2494.

25. Xu, L.; Li, J.; Cui, T.; Hu, A.; Fan, G.; Zhang, R.; Yang, H.; Sun, B.; Jonas, J.B. Refractive error in urban and rural adult Chinese in Beijing. Ophthalmology 2005, 112, 1676-1683. [CrossRef]

26. Gardiner, P.A. The relation of myopia to growth. Lancet 1954, 266, 476-479. [CrossRef]

27. Johansen, E.V. Simple myopia in schoolboys in relation to body height and weight. Acta Ophthalmol. 1950, 28, 355-361. [CrossRef]

28. Rim, T.H.; Kim, S.H.; Lim, K.H.; Kim, H.Y.; Baek, S.H. Body Stature as an Age-Dependent Risk Factor for Myopia in a South Korean Population. Semin. Ophthalmol. 2017, 32, 326-336. [CrossRef]

29. Nangia, V.; Jonas, J.B.; Matin, A.; Kulkarni, M.; Sinha, A.; Gupta, R. Body height and ocular dimensions in the adult population in rural Central India. The Central India Eye and Medical Study. Graefes Arch. Clin. Exp. Ophthalmol. 2010, 248, 1657-1666. [CrossRef]

30. Roy, A.; Kar, M.; Mandal, D.; Ray, R.S.; Kar, C. Variation of Axial Ocular Dimensions with Age, Sex, Height, BMI-and Their Relation to Refractive Status. J. Clin. Diagn. Res. JCDR 2015, 9, AC01. [CrossRef]

31. Saw, S.M.; Chua, W.H.; Hong, C.Y.; Wu, H.M.; Chia, K.S.; Stone, R.A.; Tan, D. Height and its relationship to refraction and biometry parameters in Singapore Chinese children. Investig. Ophthalmol. Vis. Sci. 2002, 43, 1408-1413.

32. Edwards, M.H. Do variations in normal nutrition play a role in the development of myopia? Optom. Vis. Sci. Off. Publ. Am. Acad. Optom. 1996, 73, 638-643. [CrossRef] [PubMed]

33. Fledelius, H.C.; Fuchs, J.; Reck, A. Refraction in diabetics during metabolic dysregulation, acute or chronic. With special reference to the diabetic myopia concept. Acta Ophthalmol. 1990, 68, 275-280. [CrossRef] [PubMed] 
34. Gwinup, G.; Villarreal, A. Relationship of serum glucose concentration to changes in refraction. Diabetes 1976, 25, 29-31. [CrossRef] [PubMed]

35. Lim, L.S.; Gazzard, G.; Low, Y.L.; Choo, R.; Tan, D.T.; Tong, L.; Yin Wong, T.; Saw, S.M. Dietary factors, myopia, and axial dimensions in children. Ophthalmology 2010, 117, 993-997. [CrossRef] [PubMed]

36. Saw, S.M.; Chia, K.S.; Lindstrom, J.M.; Tan, D.T.; Stone, R.A. Childhood myopia and parental smoking. Br. J. Ophthalmol. 2004, 88, 934-937. [CrossRef]

37. Mo, Y.; Wang, M.F.; Zhou, L.L. Risk factor analysis of 167 patients with high myopia. Int. J. Ophthalmol. 2010, 3, 80-82. [CrossRef]

38. Asakuma, T.; Yasuda, M.; Ninomiya, T.; Noda, Y.; Arakawa, S.; Hashimoto, S.; Ohno-Matsui, K.; Kiyohara, Y.; Ishibashi, T. Prevalence and risk factors for myopic retinopathy in a Japanese population: The Hisayama Study. Ophthalmology 2012, 119, 1760-1765. [CrossRef]

39. Hyman, L.; Gwiazda, J.; Hussein, M.; Norton, T.T.; Wang, Y.; Marsh-Tootle, W.; Everett, D. Relationship of age, sex, and ethnicity with myopia progression and axial elongation in the correction of myopia evaluation trial. Arch. Ophthalmol. 2005, 123, 977-987. [CrossRef]

40. Wang, D.; Huang, W.; Li, Y.; Zheng, Y.; Foster, P.J.; Congdon, N.; He, M. Intraocular pressure, central corneal thickness, and glaucoma in chinese adults: The liwan eye study. Am. J. Ophthalmol. 2011, 152, 454-462.e451. [CrossRef]

41. Wong, T.T.; Wong, T.Y.; Foster, P.J.; Crowston, J.G.; Fong, C.W.; Aung, T. The relationship of intraocular pressure with age, systolic blood pressure, and central corneal thickness in an asian population. Investig. Ophthalmol. Vis. Sci. 2009, 50, 4097-4102. [CrossRef]

42. David, R.; Zangwill, L.M.; Tessler, Z.; Yassur, Y. The correlation between intraocular pressure and refractive status. Arch. Ophthalmol. 1985, 103, 1812-1815. [CrossRef] [PubMed]

43. Han, X.; Yang, T.; Zhang, J.; Yu, S.; Guo, X.; Yan, W.; Hu, Y.; He, M. Longitudinal changes in intraocular pressure and association with systemic factors and refractive error: Lingtou Eye Cohort Study. BMJ Open 2018, 8, e019416. [CrossRef] [PubMed]

44. Lee, A.J.; Saw, S.M.; Gazzard, G.; Cheng, A.; Tan, D.T. Intraocular pressure associations with refractive error and axial length in children. Br. J. Ophthalmol. 2004, 88, 5-7. [CrossRef] [PubMed]

45. Matamoros, E.; Ingrand, P.; Pelen, F.; Bentaleb, Y.; Weber, M.; Korobelnik, J.F.; Souied, E.; Leveziel, N. Prevalence of Myopia in France: A Cross-Sectional Analysis. Med. Baltim. 2015, 94, e1976. [CrossRef] [PubMed]

46. Attebo, K.; Ivers, R.Q.; Mitchell, P. Refractive errors in an older population: The Blue Mountains Eye Study. Ophthalmology 1999, 106, 1066-1072. [CrossRef]

47. Chen, S.J.; Lu, P.; Zhang, W.F.; Lu, J.H. High myopia as a risk factor in primary open angle glaucoma. Int. J. Ophthalmol. 2012, 5, 750-753. [CrossRef] 